Aer obi c copper /TEMPO cat al yzed oxi dat i on of pri mary al cohol s to al dehydes using a microbubbl e strat egy to i ncr ease gas concent $r$ at $i$ on in I i qui d phase react $i$ ons

\begin{tabular}{|l|l|}
\hline 著者 & Nase Nobuyuki, M zumbr i Tonmya, Tat ento o Yuj i \\
\hline $\begin{array}{l}\text { j our nal or } \\
\text { publ i cat i on ti t l e }\end{array}$ & Chemi cal Communi cat i ons \\
\hline vol une & 47 \\
\hline nunber & 7 \\
\hline page range & $2086-2088$ \\
\hline year & 2011- 01- 04 \\
\hline 出版者 & Royal Soci et y of Chem st ry \\
\hline 権利 & (C) Royal Soci et y of Chem st ry 2012 \\
\hline URL & ht t p: //hdl . handl e. net /10297/6545 \\
\hline
\end{tabular}




\title{
Aerobic copper/TEMPO-catalyzed oxidation of primary alcohols to aldehydes using microbubble strategy to increase gas concentration in liquid phase reactions
}

\author{
Nobuyuki Mase,* Tomoya Mizumori and Yuji Tatemoto \\ Receipt/Acceptance Data [DO NOT ALTER/DELETE THIS TEXT] \\ Publication data [DO NOT ALTER/DELETE THIS TEXT] \\ DOI: 10.1039/b000000x [DO NOT ALTER/DELETE THIS TEXT]
}

An efficient method for the synthesis of aldehydes was achieved by using air-microbubble techniques in aerobic copper/TEMPOcatalyzed oxidation of primary alcohols. Use of air-microbubbles to improve gas absorption into liquid phase is proven to be highly beneficial for gas/liquid phase reactions.

Gas/liquid phase reactions are fundamental reaction types in material syntheses, where a number of gas molecules are employed, 15 for example, $\mathrm{O}_{2}, \mathrm{O}_{3}, \mathrm{H}_{2}, \mathrm{NH}_{3}, \mathrm{CO}_{2}, \mathrm{~F}_{2}, \mathrm{Cl}_{2}, \mathrm{CH}_{2}=\mathrm{CH}_{2}$ and $\mathrm{CH} \equiv \mathrm{CH}$ etc. The concentration of gas dissolved in liquid phase largely affects reactive properties, which inherently depends on both pressure and temperature. Although high concentrations of gas dissolved in solvent can be achieved when the reaction is ${ }_{20}$ performed under high partial pressure at low temperature, in general these conditions result in decreasing reactivity. If high concentrations of dissolved gas can be achieved at ordinary temperatures and pressures, the utility of gas/liquid phase reactions is significantly improved.

25 Recently, microbubbles have attracted attention in numerous area of study due to its characteristic features. ${ }^{1}$ For example, microbubbles exhibit excellent gas-dissolution abilities because of larger gas/liquid interfacial areas, in addition, a longer stagnation compared to conventional larger bubbles is monitored owing to its 30 small buoyancy. These phenomena cause microbubbles gradually to decrease in size, with eventually disappearance into the liquid phase.

As detailed in this communication, we propose a novel experimental methodology for gas/liquid phase reactions using 35 microbubbles (Figure 1, right), instead of conventional methods (Figure 1, left) involving vigorous stirring and/or high pressure to increase interfacial surface between gas and liquid.

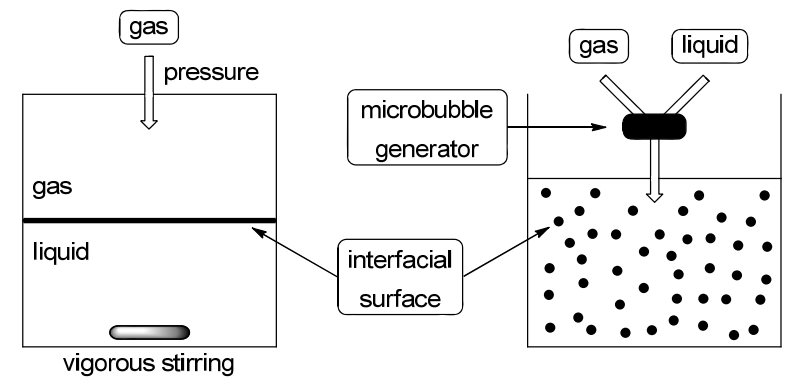

Fig. 1 Gas/liquid phase reactions

Department of Molecular Science, Faculty of Engineering, Shizuoka University, 3-5-1 Johoku, Hamamatsu 432-8561, Japan. Fax: +81-53478-1196; Tel: +81-53-478-1196; E-mail: tnmase@ipc.shizuoka.ac.jp $\dagger$ Electronic Supplementary Information (ESI) available: Experimental procedure. See http://dx.doi.org/10.1039/b000000x/
40 Prior to starting this project, a special microbubble generator, which is resistant to corrosion with acid-, base-, and organic solvent, was required. Furthermore, a small microbubble generator was desired for an academic laboratory setting, though larger generators (pumping rate $>10 \mathrm{~L} / \mathrm{min}$ ) have been already commercially 45 available. In cooperation with Asupu Company Limited, stainless steel-components from a small generator were replaced with Teflon $^{\circledR}$ (MA2-FS, pumping rate $120-150 \mathrm{~mL} / \mathrm{min}$, Figure 2, upper right).

Performance evaluations measuring dissolved oxygen levels in ${ }_{50}$ distilled water showed that the Teflon ${ }^{\circledR}$-microbubble generator rapidly supersaturated with respect to oxygen at an air-flow rate of $3 \mathrm{~mL} / \mathrm{min}$ without stirring. The solution of water saturated with oxygen appeared cloudy (Figure 2, lower right). After stopping the air supply for 20 minutes, it remained oversaturated for 40 minutes 55 (Figure 2). On the other hand, air bubbling at an air-flow of rate 3 $\mathrm{mL} / \mathrm{min}$ using a conventional gas dispersion tube with porous fritted glass tip resulted in low saturation of oxygen in solution after 60 minutes with vigorous stirring. This result is similar to that without air bubbling. These outcomes indicate that a Teflon ${ }^{\mathbb{B}}$ 60 microbubble generator is an efficient instrument to dissolve oxygen into distilled water.

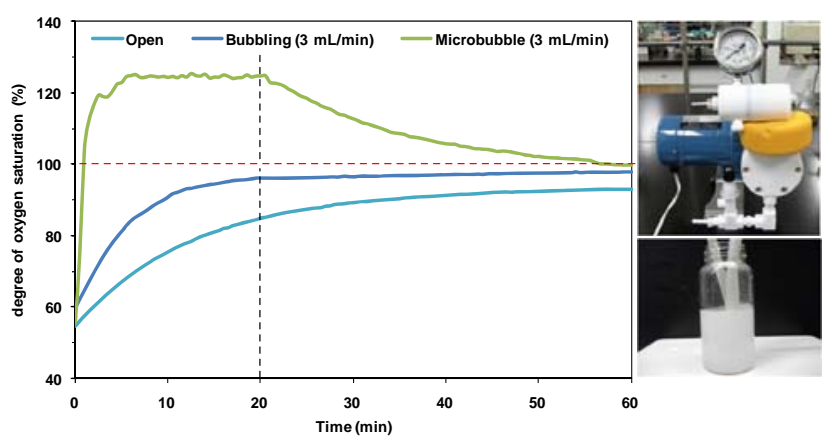

Fig. 2 Microbubble generator and degree of oxygenation in distilled water 65

Encouraged by these basic results, we started to investigate novel microbubble strategies for gas/liquid phase reactions. The aerobic copper/2,2,6,6-tetramethylpiperidine $N$-oxyl (TEMPO)-catalyzed oxidation of primary alcohols $(20 \mathrm{mmol})$ to aldehydes developed 70 by the Sheldon group was chosen as a model reaction Table 1.,3,4 First attempts under Sheldon's condition with microbubbling (airflow rate: $3 \mathrm{~mL} / \mathrm{min}$ ) afforded the desired benzaldehyde (2a) in $81 \%$ conversion without formation of carboxylic acid (3a) (entry 1). Catalytic activity was improved by the addition of 2,2-bipyridine 75 (4b) and $\mathrm{MeONa}$ (5b), in which conversion to the aldehyde 
increased to $93 \%$ at $30{ }^{\circ} \mathrm{C}$ (entries $\left.1-4\right)$. Air was replaced by $\mathrm{O}_{2^{-}}$ microbubbles in the oxidation of alcohol 1a, a similar result was observed (entry 4 vs. 5). On the other hand, poor conversion of alcohol 1a to aldehyde 2a (30\%) was observed under open 80 conditions after 2 hours of vigorous stirring (entry 6). In addition, air bubbling (air-flow rate: $3 \mathrm{~mL} / \mathrm{min}$ ) using a conventional gas dispersion tube fitted with a porous fritted glass tip resulted in $48 \%$ conversion (entry 7). Even when air-flow rate was up to 15 $\mathrm{mL} / \mathrm{min}$, conversion was lower than microbubbling procedure ${ }_{85}$ (entry 4 vs. 8). Condensers must be attached to the reaction vessel when reactions are performed at high gas-flow rates such as 15 $\mathrm{mL} / \mathrm{min}$, whereas microbubbling procedures do not require similar engineering controls.

90 Table 1. Aerobic copper/TEMPO-catalyzed oxidation of benzyl alcohol (1a) to benzaldehyde (2a) $)^{a}$

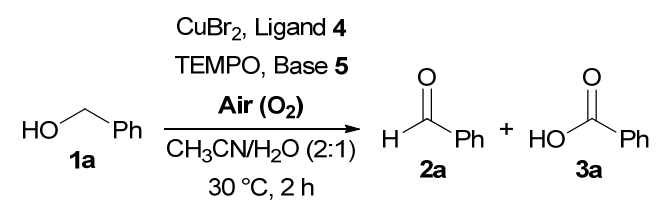

Ligand: 1,10-phenanthroline (4a), 2,2'-bipyridine (4b)

Base: $t$-BuOK (5a), $\mathrm{MeONa}(5 \mathbf{b})$

\begin{tabular}{|c|c|c|c|c|}
\hline Entry & Ligand & Base & Bubbling (mL/min) & Conversion (\%) \\
\hline$\overline{1}$ & $4 a$ & $5 a$ & microbubbling (3) & 81 \\
\hline 2 & 4a & $5 \mathbf{b}$ & microbubbling (3) & 87 \\
\hline 3 & $4 b$ & $5 a$ & microbubbling (3) & 90 \\
\hline 4 & $4 b$ & $5 b$ & microbubbling (3) & 93 \\
\hline 5 & $4 b$ & $5 b$ & microbubbling $(3)^{c}$ & 94 \\
\hline 6 & $4 b$ & $5 b$ & open $(0)^{d}$ & 30 \\
\hline 7 & $4 b$ & $5 \mathbf{b}$ & bubbling $(3)^{d}$ & 48 \\
\hline 8 & $4 b$ & $5 b$ & bubbling $(15)^{d}$ & 84 \\
\hline
\end{tabular}

${ }^{a}$ Conditions: See Notes and references. ${ }^{\mathrm{b}}$ Determined by GC-analyses (column: GL Sciences TC-17). ${ }^{c} \mathrm{O}_{2}$-microbubble was used instead of air-

95 microbubble. ${ }^{d}$ These reactions were carried out with vigorous stirring.

The scope of this class of microbubble oxidation was examined with a series of benzyl alcohol derivatives 1 under the optimized conditions and the results are summarized in Table 2. ${ }^{5}$ Aromatic 100 aldehydes 2 were obtained in good to excellent yields within 4 hours at $30^{\circ} \mathrm{C}$. Overoxidation from aldehyde to carboxylic acid was not observed.

Table 2. Aerobic copper/TEMPO-catalysed oxidation of alcohols 1 to 105 aldehydes $\mathbf{2}^{a}$

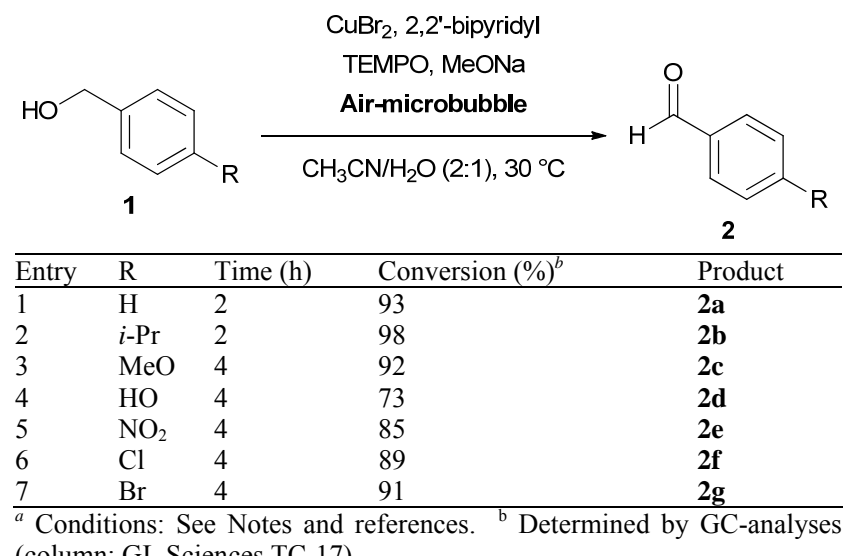

(column: GL Sciences TC-17).
110 The microbubble oxidation system displayed a preference for primary versus secondary alcohols (10 mmol each) according to intermolecular competition experiments (Scheme 1). ${ }^{6}$ Corresponding benzaldehyde (2a) and acetophenone (7) were obtained in $99 \%$ and $3 \%$ conversion, respectively, after 30 minutes 115 under optimized air-microbubbling conditions. As expected, poor conversion to the aldehyde 2a was observed using standard airbubbling and stirring conditions. Therefore, primary alcohols were selectively oxidized in the presence of secondary alcohols in the microbubble oxidation system with excellent conversion. 120

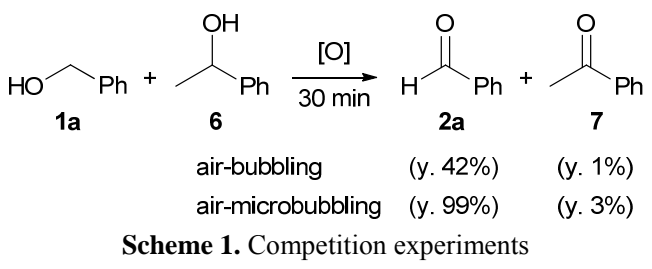

We next examined microbubble oxidation using aliphatic 125 alcohols as substrates. The allylic alcohol geraniol (8) was an excellent substrate giving geranial (9) in 99\% conversion with high regioselectivity $((E):(Z)=99: 1)$ with a short reaction time $(1 \mathrm{~h})$. Standard work-up and reduced-pressure distillation afforded geranial (9) in $84 \%$ yield and $97 \%$ purity as determined by GC 130 analysis. In contrast, oxidation with conventional air-bubbling techniques resulted in only $74 \%$ conversion (Scheme 2 ). The cyclic monoterpene allyl alcohol myrtenol (10) was also oxidized to myrtenal (9) in $99 \%$ conversion under the same microbubble conditions (Scheme 2). These exceptional results show the broad 135 potential of our microbubble strategy in aerobic oxidation of primary alcohols.
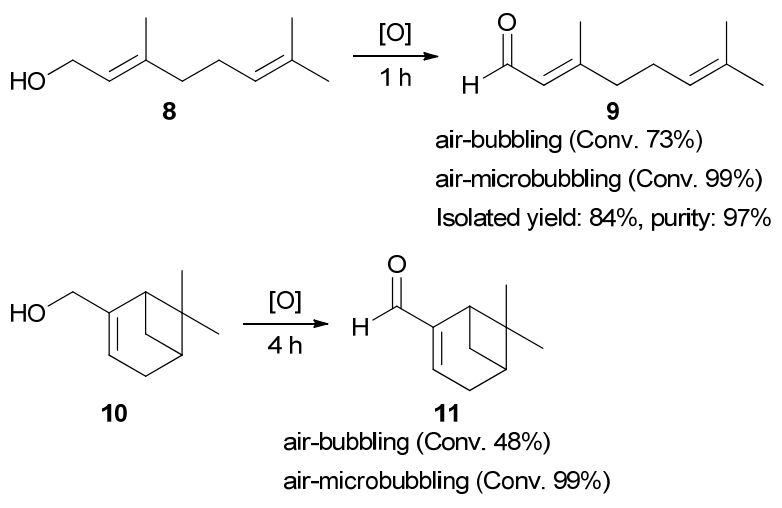

Scheme 2. Aerobic copper/TEMPO-catalyzed oxidation of aliphatic alcohol with microbubble procedure

Aerobic copper/TEMPO-catalyzed oxidation of unmodified aliphatic primary alcohols has great utility in organic synthesis due to their low reactivity, ${ }^{4}$ oxidation of 1-octanol carried out by both 145 microbubbling and conventional air-bubbling procedure furnished 1-octanal in almost same conversion (72\% and $74 \%$, respectively) after prolonged reaction time $(12 \mathrm{~h}) .^{7}$ This is an undesirable result for us, but it suggests that air- and/or $\mathrm{O}_{2}$-microbubble techniques do not accelerate the rate-determining step but have more effect on the 150 regeneration steps of TEMPO from TEMPOH. The Sheldon group has proposed the mechanism of aerobic copper/TEMPO-oxidations as shown in Scheme 3. ${ }^{2}$ Hydrogen abstraction from the $\alpha$-carbon 
atom by TEMPO ( $\mathbf{C}$ to $\mathbf{D}$ in Scheme 3 ) is the rate-determining step (RDS); therefore, oxidation of an unmodified aliphatic primary 155 alcohol is expected to be much slower than that of benzylic and allylic alcohols. Consequently, the highly oxygenated water present due to air-microbubbling has almost no effect on the ratedetermining step. However, it probably accelerates regeneration of TEMPO from TEMPOH during the proposed catalytic cycle in 160 Scheme 3.

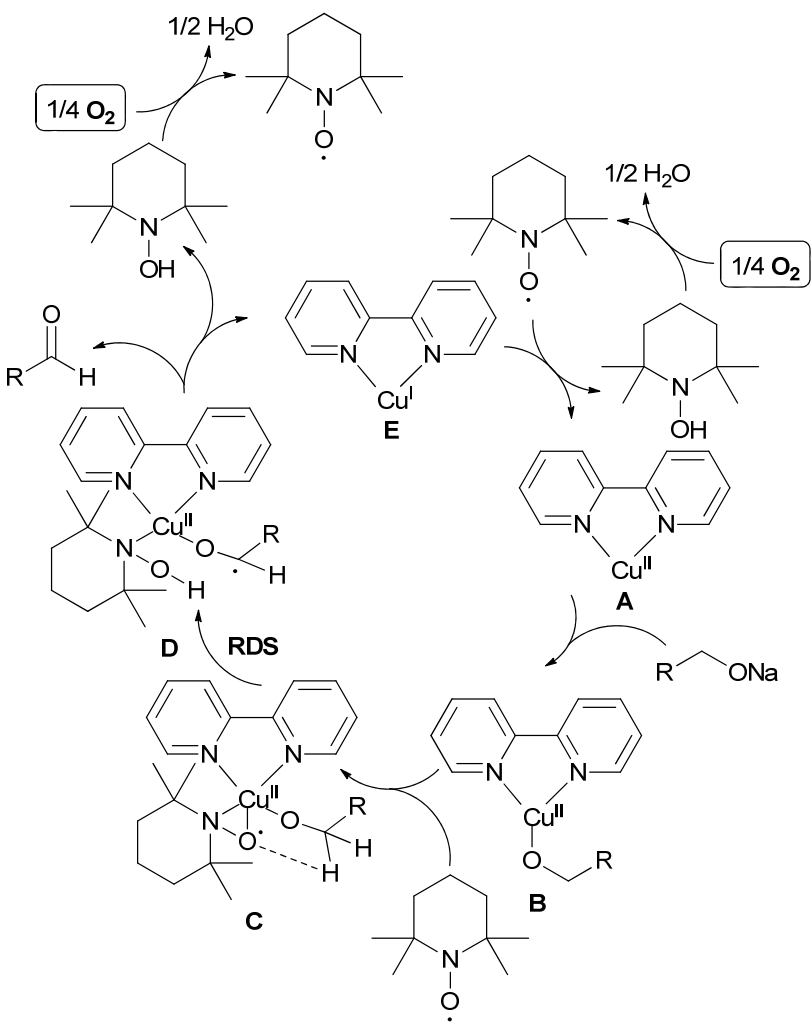

Scheme 3 Sheldon's proposed oxidation mechanism

165 In addition, the Koskinen group suggested a different reaction species, a binuclear copper(II) complex $\mathbf{G}$, which is derived from a monomeric species $\mathbf{F}$ in the presence of molecular oxygen (Scheme 4). ${ }^{4 c}$ In both Schemes 3 and 4 molecular oxygen $\left(\mathrm{O}_{2}\right)$ is a key to oxidizing to form reactive species, hence high concentrations of 170 dissolved $\mathrm{O}_{2}$ should significantly affect the reaction efficiency.
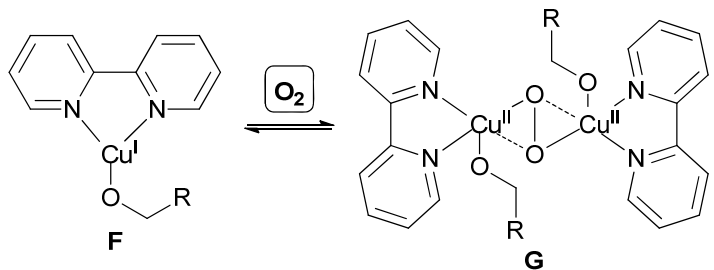

Scheme 4 Koskinen's proposed a binuclear copper (II) complex

175 In summary, we have developed novel experimental methodology by using microbubbles for gas/liquid phase reactions in organic synthesis. The exact role of microbubbles remains unclear, ${ }^{8}$ however; our strategy showed improved efficiency on the aerobic copper/TEMPO-catalyzed oxidation of primary alcohols to 180 aldehydes. Further studies focusing on the full scope of this unique microbubble system are currently under investigation and will be reported in due course. ${ }^{9}$ In addition, since this new microbubblesystem could potentially use for any gas/liquid phase reactions at least in principle, we believe that this study is an important 185 contribution to all gas/liquid phase reactions including not only present aerobic oxidation but also hydrogenation, ozonation, reductive amination, halogenation, etc. under environmentallyfriendly protocols and are currently under investigation.

\section{Acknowledgements}

190 We gratefully acknowledge Dr. D. D. Steiner for a scientific discussion. Thanks to Shiono Koryo Kaisha, Ltd. for a generous gift of alcohols and aldehydes. This study was supported in part by a Grant-in-Aid for Exploratory Research from the Japan Society for the Promotion of Science.

\section{${ }_{195}$ Notes and references}

1 (a) E. Stride and M. Edirisinghe, Soft Matter, 2008, 4, 2350-2359. (b) Y.-z. Hu, J.-a. Zhu, Y.-g. Jiang and B. Hu, Advances in Therapy, 2009, 26, 425-434. (c) I. Lentacker, S. S. C. De and N. N. Sanders, Soft Matter, 2009, 5, 2161-2170.

2002 P. Gamez, I. W. C. E. Arends, R. A. Sheldon and J. Reedijk, Adv. Synth. Catal., 2004, 346, 805.

3 Reviews: (a) R. A. Sheldon and I. W. C. E. Arends, Adv. Synth. Catal., 2004, 346, 1051. (b) R. Ciriminna and M. Pagliaro, Org. Process Res. Dev., 2009, 14, 245.

2054 Recent aerobic TEMPO-catalyzed oxidation of primary alcohols to aldehydes: (a) W. Yin, C. Chu, Q. Lu, J. Tao, X. Liang and R. Liu, Adv. Synth. Catal., 2010, 352, 113. (b) C.-X. Miao, L.-N. He, J.-L. Wang and F. Wu, J. Org. Chem., 2010, 75, 257. (c) E. T. T. Kumpulainen and A. M. P. Koskinen, Chem. Eur. J., 2009, 15, 10901.

210 (d) P. J. Figiel, A. Sibaouih, J. U. Ahmad, M. Nieger, M. T. Räisänen, M. Leskelä and T. Repo, Adv. Synth. Catal., 2009, 351, 2625. (e) G. Yang, W. Zhu, P. Zhang, H. Xue, W. Wang, J. Tian and M. Song, Adv. Synth. Catal., 2008, 350, 542. (f) X. Wang, R. Liu, Y. Jin and X Liang, Chem. Eur. J., 2008, 14, 2679-2685. (g) N. Jiang and A. J.

215 Ragauskas, ChemSusChem, 2008, 1, 823. (h) Y. Xie, W. Mo, D. Xu, Z. Shen, N. Sun, B. Hu and X. Hu, J. Org. Chem., 2007, 72, 42884291. (i) S. Mannam, S. K. Alamsetti and G. Sekar, Adv. Synth. Catal., 2007, 349, 2253-2258. (j) B. Karimi, A. Biglari, J. H. Clark and V. Budarin, Angew. Chem., Int. Ed., 2007, 46, 7210. (k) C. W. Y. Chung and P. H. Toy, J. Comb. Chem., 2007, 9, 115-120.

5 Typical procedure for aerobic copper/TEMPO-catalyzed oxidation of primary alcohols 1 to aldehydes $\mathbf{2}$ using microbubble strategy: The oxidation was carried out in a $50 \mathrm{~mL}$ vial equipped with a microbubble generator without additional stirring. The alcohol 1 (20 $225 \mathrm{mmol})$ was dissolved in $\mathrm{CH}_{3} \mathrm{CN} / \mathrm{H}_{2} \mathrm{O}(2: 1,30 \mathrm{~mL})$, then warmed to $30{ }^{\circ} \mathrm{C}$. To the solution NaOMe $(5 \mathbf{b}, 81 \mathrm{mg}, 1.5 \mathrm{mmol})$ and $\mathrm{CuBr}_{2}$ (215 mg, $1.5 \mathrm{mmol}$ ) were added, resulting in a light blue suspension. After addition of 2,2-bipyridine (4b, $234 \mathrm{mg}, 1.5 \mathrm{mmol})$ to the suspension, colour was changed to blue-green. To the mixture TEMPO (313 mg, $2.0 \mathrm{mmol}$ ) was added, leading to a red-brown mixture. Air-microbubble was introduced into the reaction mixture by microbubble generator (MA2-FS) at air-flow rate $3 \mathrm{~mL} / \mathrm{min}$. The red-brown mixture gradually turned dark-green. Samples $(0.5 \mathrm{~mL}$ which were extracted with $\mathrm{Et}_{2} \mathrm{O}$ ) of the reaction mixture were taken out to monitor the reaction by GC analysis. The products 2 were determined by comparison with the commercially available aldehydes.

6 Acetophenone (11) was obtained in $13 \%$ conversion after $2 \mathrm{~h}$ using microbubble system in oxidation of the secondary alcohol (air-flow rate $3 \mathrm{~mL} / \mathrm{min}$ ).

7 These reactions were carried out using $\mathrm{CuBr}_{2}(10 \mathrm{~mol} \%)$, ligand $4 \mathbf{b}$ (10 mol\%), TEMPO $(12.5 \mathrm{~mol} \%)$ and base $5 \mathbf{b}(10 \mathrm{~mol} \%)$ in $\mathrm{CH}_{3} \mathrm{CN} / \mathrm{H}_{2} \mathrm{O}(2: 1)$ for $12 \mathrm{~h}$. 
8 Local "hot spot" theory is probably another possibility, however; positive effect was not reported in study of decomposition of perfluorooctanoic acid. M. Takahashi, K. Chiba and P. Li, J. Phys. Chem. B, 2007, 111, 1343.

9 Preliminary results were discussed at the 2010 summer symposium of the Japanese Society for Process Chemistry, 1P-32 on July 15, 2010. 
